Journal of Thermal Engineering, Vol. 5, No. 5, pp. 446-455, October, 2019

Yildiz Technical University Press, Istanbul, Turkey

\title{
THERMAL EVALUATION OF CAVITY RECEIVER USING WATER/PG AS THE SOLAR WORKING FLUID
}

\author{
R. Loni1 ${ }^{1,2}$, A. Kasaeian ${ }^{3,}$, E. Askari Asli-Ardeh${ }^{1}$, B. Ghobadian², G. Najafi²
}

\begin{abstract}
In this study, a parabolic dish concentrator with a cavity receiver was investigated. Water/ Propylene Glycol (PG) was used as the solar heat transfer fluid. Thermal numerical modelling was developed for prediction of the cavity receiver performance. The water/PG in different volume fractions (VF) of the PG was examined consist of $0 \%, 25 \%$, $50 \%$, and $55 \%$. The working fluid inlet temperature is investigated in ranging $0^{\circ} \mathrm{C}$ to $100^{\circ} \mathrm{C}$. The results revealed that the thermal efficiency and the cavity heat gain decreased by increasing the GP volume fraction. The pressure drop and pumping work demand decreased by increasing the working fluid inlet temperature as well as decreasing the PG volume fraction in the pure water. Consequently, the pure water had the lowest amount of the pressure drop among the investigated working fluids. The cavity surface temperature increased by increasing the working fluid inlet temperature as well as increasing the PG volume fraction in the pure water. Consequently, the application of the higher amount of PG is recommended for the Bryton cycle.
\end{abstract}

\section{Keywords: Numerical Modelling, Cavity Receiver, Energy Analysis, Propylene Glycol}

\section{INTRODUCTION}

One effective solution for reducing alleviating environmental problems due to fossil fuel consumption such as emissions of $\mathrm{CO}, \mathrm{CO}_{2}$, global warming, and ozone depletion is the application of the renewable energy technologies. In this regard, the solar energy is accounted as an associability and important renewable energy. The hourly solar irradiation on the Earth's surface is more significant than all of the human consumption of energy in a year [1]. Solar collectors are a kind of technology for converting the solar radiation energy to the internal energy of the solar working fluids. The solar collectors divided into flat plate collectors and concentrated collectors. In the recent years, the research works have increased on the concentrated solar energy systems [2-4]. Dish concentrator is a kind of the concentrator collectors. The dish collector concentrates the incoming solar radiation in the focal point where the solar receiver is located. There are different types of the receiver for dish concentrator that include the volumetric, particle, tubular cavity, and spiral absorber receivers [5-8]. The tubular cavity receivers because of particular structure have higher efficiency compared to the external receivers $[9,10]$. Some researchers have numerically investigated the cavity receivers [11-13]. Li et al. [14] studied the numerical optimization of a dish collector using cavity and flat receivers. They concluded that a windowed-cavity receiver has better performance than the flat receivers. Jilte et al. [15] considered different shapes of the cavity receiver using numerical methods. They proposed Nusselt number equations for the different shapes of cavity receiver under the windy weather condition. Prakash et al. [16] researched a cylindrical cavity receiver numerically and experimentally. They considered the impacts of the working fluid inlet temperature, wind speed, and cavity inclination angle. They presented a Nusselt number for convection heat loss from the investigated cylindrical cavity receiver. Reddy et al. [17] evaluated a dish concentrator using a modified cavity receiver using a numerical method. They predicted a Nusselt number for the combination of the convection and radiation heat losses from the investigated cavity receiver. The effect of wind speed was numerically and experimentally considered by [10]. They presented some models for prediction of the forced convection in a hemispherical cavity receiver. In some studies, researchers have considered the application of different nanofluids in cavity receivers [3, 11]. Loni et al. [13] predicted the cavity thermal performance using ANN method. They showed

This paper was recommended for publication in revised form by Regional Editor Omid Mahian

${ }^{1}$ Department of Biosystems Engineering, University of Mohaghegh Ardabili, Ardabil, Iran.

${ }^{2}$ Department of Biosystems Engineering, Tarbiat Modares University, Tehran, Iran.

${ }^{3}$ Department of Renewable Energies, Faculty of New sciences \& Technologies, University of Tehran, Tehran, Iran.

*E-mail address: akasa@ut.ac.ir

Orcid id: 0000-0003-2801-2428, 0000-0002-4340-190X, 0000-0002-4048-2046, 0000-0003-4221-5950, 0000-0003-3125-3804

Manuscript Received 9 February 2018, Accepted 8 April 2018 
an accurate prediction of the thermal performance using ANN method. A comprehensive review was presented by $\mathrm{Wu}$ et al. [18] about the convection heat losses from a dish concentrator using cavity receiver. Simulation and optimization of a concentrator collector using a receiver were carried out by Przenzak et al. [19]. They applied optical methods and computational fluid dynamics for their simulation. The best location for the receiver on the concentrator collector was determined during their study. They evaluated the receiver wall temperature and the working fluid temperature using computational fluid dynamics method. Kaushika and Reddy [20] worked a dish collector using cavity receiver for the power generation application. They studied the thermal performance optimization for a semicavity receiver. Mao et al. [21] investigated a dish collector with a cavity receiver. The impact of the different parameters such as incident solar irradiation, aspect ratio, and optical error was evaluated on the solar heat flux distribution. They concluded that the aspect ratio and optical error were accounted as the effective parameters on the solar flux distribution. Loni et al. [6,7] analytically investigated different shapes of cavity receivers. The presented the optimum structure of the cavity receivers. In other works, Loni et al. $[8,12]$ thermodynamically and energetically studied a solar ORC system using cavity receivers. They reported the effect of different structural and operational parameters on the ORC performance.

Fang et al. [22] numerically studied the thermal performance of a cavity receiver. They applied a combined calculation method in their research. They concluded that the highest heat loss is accrued when the wind blows in parallel direction compared to the cavity aperture. Reddy and Kumar [23] evaluated the natural convection heat loss of a modified cavity receiver numerically. There was a good agreement between their predicted results of the investigated model and other well-known models results. Chang et al. [24] numerically considered the thermal performance of a modified cavity receiver. The solar system constructed from a cavity receiver with a glass cover and a secondary reflection. They concluded that the glass cover application at the cavity aperture and the implementation of the second reflection surface could improve the thermal performance of the investigated solar dish collector. Pavlovic et al. [25] numerically and experimentally examined a spiral cavity receiver as the solar receiver in the dish concentrator.

It can be observed from the literature review that there is no reported paper of application water + PG as the solar working fluid in a hemispherical cavity receiver. Therefore, the novelty of the current study is numerically investigation of the hemispherical cavity receiver using the water + PG in different volume fractions of PG in the pure water. The thermal performance of the investigated hemispherical cavity receiver is considered. During the study, various parameters are examined consist of the cavity heat gain, thermal efficiency, pressure drop, and cavity wall temperatures.

\section{Simulation and Methodology}

Hemispherical cavity receiver is investigated in this study. The working fluid flows from the bottom to the top of the investigated cavity receiver. According to Le Roux et al. [26], the contributing parameters to the temperature profile and the heat flow on the receiver wall can be separated into two components: geometry-dependent and temperature-dependent. Their research has shown that the effects of the geometry-dependent factors can be found with SolTrace software as an optical analysis tool. The temperature-dependent factors including radiation, convection, and thermal conduction losses can be calculated using a thermal model. The same methodology has been applied in this work.

\section{Optical Modeling}

The optical analysis is conducted using the commercial software SolTrace. This tool uses the Monte Carlo ray tracing method to perform the optical analysis. The heat flux rate over each coil of the absorber is found separately and finally, the total absorbed heat rate is found by adding the absorbed heat rate of each coil. Table 1 gives more details about the optical analysis of the hemispherical cavity. 
Table 1. SolTrace modelling assumptions

\begin{tabular}{|l|l|}
\hline Parameter & Value \\
\hline The reflectance of the cavity walls & 0.15 \\
\hline The optical errors & $10 \mathrm{mrad}$ \\
\hline The tracking error & $1^{\circ}$ \\
\hline The half-angle width & $4.65 \mathrm{mrad}$ \\
\hline The sun-shape & Pillbox \\
\hline
\end{tabular}

\section{Thermal Modeling}

The developed thermal model is based on the determination of the cavity`s thermal losses which includes radiation, convection, and conduction. The cavity is insulated with mineral wool. The thermal losses have been calculated using a mean surface temperature close to $200^{\circ} \mathrm{C}$ as an initial value. The developed numerical model is described in detail below. The net heat transfer rate $\left(\dot{Q}_{n e t}\right)$ can be defined as subtracting the absorbed solar energy from cavity heat losses including the convection, conduction, and radiation heat losses. The net heat transfer rate is calculated using Equations (1-3):

$$
\begin{gathered}
\dot{Q}_{n e t}=\dot{Q}^{*}-\dot{Q}_{\text {loss,cond }}-\dot{Q}_{\text {loss }, \text { rad }}-\dot{Q}_{\text {loss }, \text { conv }} \\
\dot{Q}^{*}=\eta_{\text {optical }} \eta_{\text {refl }} \dot{Q}_{\text {solar }} \\
\dot{Q}_{\text {solar }}=I_{\text {sun }} \pi D_{\text {conc }}^{2} / 4
\end{gathered}
$$

In the current study, the value of $\dot{Q}^{*}$ (the solar heat transfer rate) was calculated using the SolTrace software. The total incoming the solar irradiation $\left(\dot{Q}_{\text {solar }}\right)$ was determined using Eq. 3 . In these equations, $\eta_{\text {optical }}$ is the optical efficiency, $\eta_{\text {refl }}$ is the dish reflectivity, which is equal to $0.84, \dot{Q}_{\text {solar }}(\mathrm{W})$ is the solar heat transfer rate available at the dish concentrator, $I_{\text {sun }}$ is the solar beam irradiance, which is equal to $800 \mathrm{~W} / \mathrm{m}^{2}$. Also, $D_{\text {conc }}$ is the dish aperture diameter, which is equal to $1.8 \mathrm{~m}$. Moreover, $\dot{Q}_{\text {loss,cond }}(\mathrm{W}), \dot{Q}_{\text {loss,rad }}(\mathrm{W})$ and $\dot{Q}_{\text {loss,conv }}(\mathrm{W})$ are the conduction, radiation, and convection thermal heat losses of the receiver, respectively.

For thermal modelling, the cavity tube is divided into elements where each coil of the cavity tube is assumed as an element. The receiver surface temperature $\left(T_{s, n}\right)$ and the useful heat transfer rate $\left(\dot{Q}_{n e t, n}\right)$ at the different elements of the tube are calculated by solving Equations (4) and (6) with the Newton-Raphson Method using the Maple software:

$$
\dot{Q}_{n e t, n}=\frac{\left(T_{s, n}-\sum_{i=1}^{n-1}\left(\frac{\dot{Q}_{n e t, i}}{\dot{m} c_{p 0}}\right)-T_{\text {inlet }, 0}\right)}{\left(\frac{1}{h_{\text {inner }} A_{n}}+\frac{1}{2 \dot{m} c_{p 0}}\right)}
$$

The net heat transfer rate can be calculated using the following equations:

$$
\dot{Q}_{n e t, n}=\dot{Q}_{n}^{*}-\dot{Q}_{l o s s, r a d, n}-\dot{Q}_{l o s s, c o n v, n}-\dot{Q}_{l o s s, c o n d, n}
$$




$$
\begin{gathered}
\dot{Q}_{n e t, n}=\dot{Q}_{n}^{*}-A_{n} \varepsilon_{n} \sigma\left(T_{s, n}{ }^{4}\right)+A_{n} \sum_{j=1}^{N} F_{n-j} \varepsilon_{j} \sigma\left(T_{s, n}{ }^{4}\right)-A_{n} \varepsilon_{n} \sigma F_{n-\infty} T_{\infty}^{4} \\
-A_{n}\left(m_{2} T_{s, n}+c_{2}\right)-\frac{A_{n}}{R_{\text {cond }}}\left(T_{s, n}-T_{\infty}\right)
\end{gathered}
$$

Finally, after calculation of the useful heat transfer rate $\left(\dot{Q}_{n e t, n}\right)$ at different elements of the tube, the thermal efficiency of the investigated cavity receiver is calculated as followings:

$$
\eta_{t h}=\sum_{n=1}^{N} \dot{Q}_{n e t, n} / \dot{Q}_{\text {solar }}
$$

The receiver aperture size, the mass flow rate of the working fluid, the receiver tube diameter, and the working fluid inlet temperature are parameters that influence the receiver surface temperature and net heat transfer rate at different positions along the tube length. The dish reflectivity, the direct normal beam irradiance (DNI) and the reflector surface optical error are optical parameters which affect the thermal efficiency of the system. Note that each coil of the cavity receiver is considered to be a separate receiver element. All of the thermal modelling as some codes were written in the Maple software. The properties of the PG are presented in Table 2.

Table 2. The properties of the PG

\begin{tabular}{|l|l|}
\hline Chemical formula & $\mathrm{C}_{3} \mathrm{H}_{8} \mathrm{O}_{2}$ \\
\hline Molar mass & $76.10 \mathrm{~g} \cdot \mathrm{mol}^{-1}$ \\
\hline Density & $1.036 \mathrm{~g} / \mathrm{cm}^{3}$ \\
\hline Melting point & $-59^{\circ} \mathrm{C}$ \\
\hline Boiling point & $188.2^{\circ} \mathrm{C}$ \\
\hline
\end{tabular}

On the other hand, the total pressure drop can be estimated using Equations $(\mathbf{8})$ and $(\mathbf{9})[6,26,27]$ :

$$
\begin{aligned}
& \Delta P=\frac{\rho\left(V^{2}{ }_{A v g}\right)}{2}\left(f_{r} \frac{L}{d}+\sum_{y} K_{y}\right) \\
& \Delta P=\frac{8 \dot{m}^{2}}{\rho \pi^{2} d^{4}}\left(f_{r} \frac{L}{d}+\sum_{y} K_{y}\right)
\end{aligned}
$$

The pumping work demand is defined as followings:

$$
\dot{W}_{\text {pump }}=\Delta P V_{f}
$$

where $V_{f}$ is the volume flow rate $\left(\mathrm{m}^{3} / \mathrm{s}\right)$ of the solar working fluid, which has a constant value of $100 \mathrm{ml} / \mathrm{s}$, in the current study.

\section{RESULTS AND DISCUSSION}

The variation of the cavity heat gain versus the variation of the working fluid inlet temperature is shown in Figure 1. As previously mentioned, three different volume fractions of the PG (25\%, 50\%, and 55\%) are considered. It can be seen from Figure 1 that the cavity heat gain decreases with increasing the working fluid inlet temperature. This matter is mentioned by other researchers, too [6, 7, 26]. Also, it can result from Figure 1 that the cavity heat gain decreases by increasing the GP volume fraction in the water. In the other word, pure water achieves the highest amount 
of cavity heat gain among the investigated solar working fluids. This issue is due to the decreasing the heat capacity and the thermal conductivity of the working fluid by increasing the PG volume fraction (see Figures A1 and A2 in Appendix A).

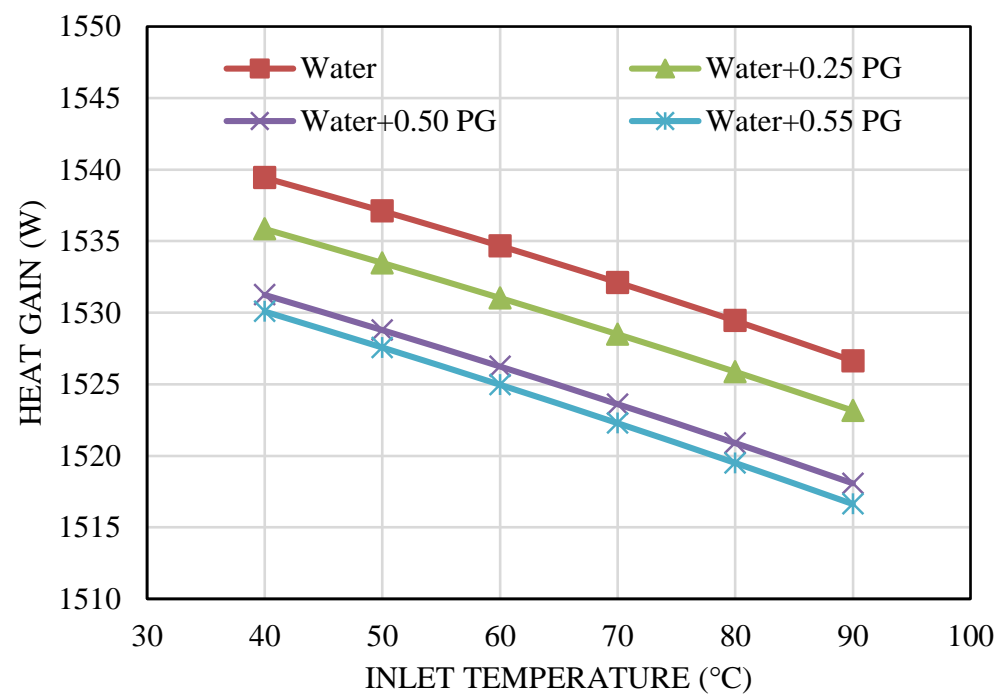

Figure 1. Variation of the cavity heat gain versus the variation of the working fluid inlet temperature in different volume fraction of the PG

Figure 2 depicts the variation of the cavity thermal efficiency versus the variation of the working fluid inlet temperature in the different volume fractions of the PG. It would be seen that the thermal efficiency of the investigated hemispherical cavity receiver decreases with increasing the working fluid inlet temperature. This issue is due to the reducing cavity heat gain by increasing the inlet temperature (see Figure 1). Also, it is understood from Figure 1 that the thermal efficiency of the investigated solar system decreases with increasing the GP volume fraction in the water. The reason for this matter is the decreasing the cavity heat gain by increasing the PG volume fraction in the water. Consequently, the thermal efficiency of the investigated hemispherical cavity receiver has the highest amount using the pure water among the investigated solar working fluids.

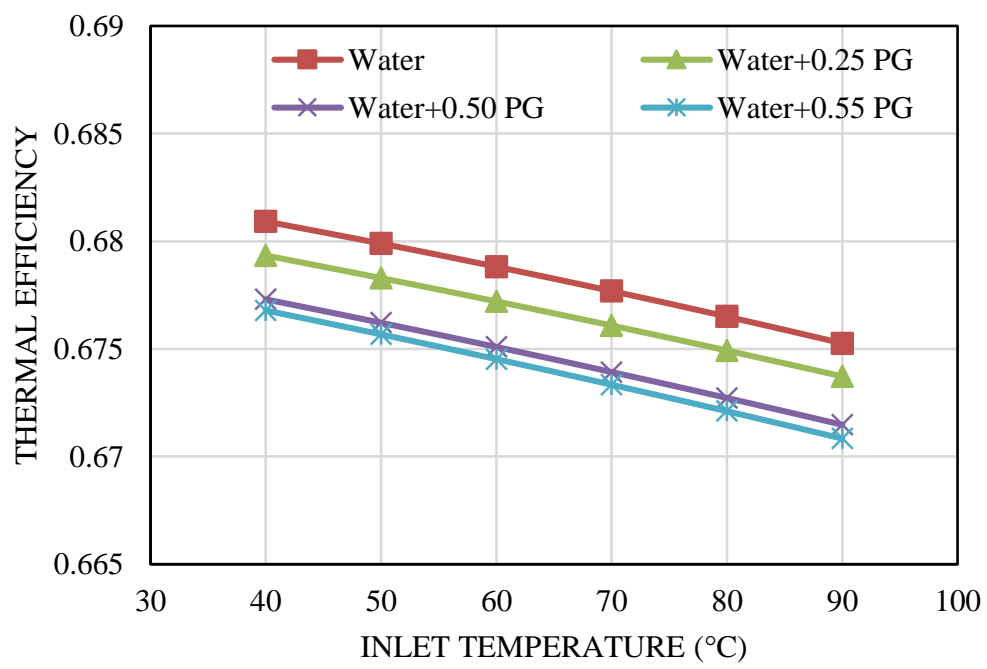

Figure 2. Variation of the thermal efficiency versus the variation of the working fluid inlet temperature in different volume fraction of the PG 
The variation of the average surface temperature versus the variation of the working fluid inlet temperature is presented in Figure 3 for the different amount of PG volume fraction (25\%, 50\%, and 55\%). It is seen from Figure 3 that the cavity surface temperature is increased with increasing the working fluid inlet temperature. Also, it could result from Figure 3, the average surface temperature of the hemispherical cavity receiver increases with increasing the PG volume concentration in the pure water. Consequently, the application of the higher amount of PG is recommended for the Bryton cycle.

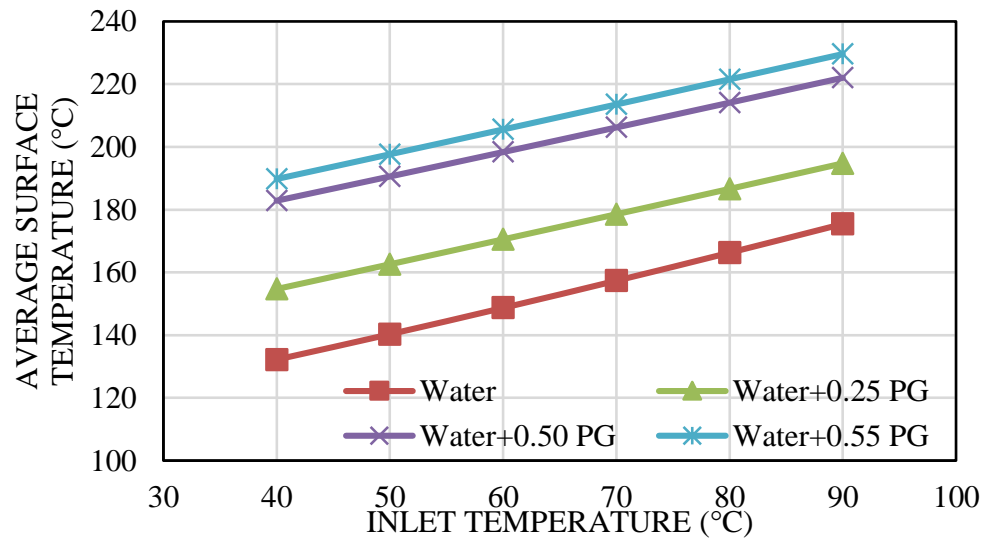

Figure 3. Variation of the average surface temperature versus the variation of the working fluid inlet temperature in different volume fraction of the PG

Figure 4 presents the variation of the pressure drop versus the variation of the working fluid inlet temperature in the different amount of the PG volume fractions $(25 \%, 50 \%$, and 55\%). It could result from Figure 4 that the pressure drop decreases with increasing the working fluid inlet temperature. Also, it is seen that the pressure drop increases with increasing the PG volume fraction. In the other word, the pure water has the lowest amount of the pressure drop among the investigated working fluids. This matter is due to the increasing the density of the working fluid by increasing the PG volume fraction (see Figure A3 in Appendix A). Pumping work demand versus the variation of the working fluid inlet temperature in different volume fraction of the PG is presented in Figure 5. As seen, the pumping work demand shows similar manner compared to the pressure drop. In the other word, the pumping work demand decreased with increasing the cavity inlet temperature as well as decreasing volume fraction of the PG in the water as the solar working fluid.

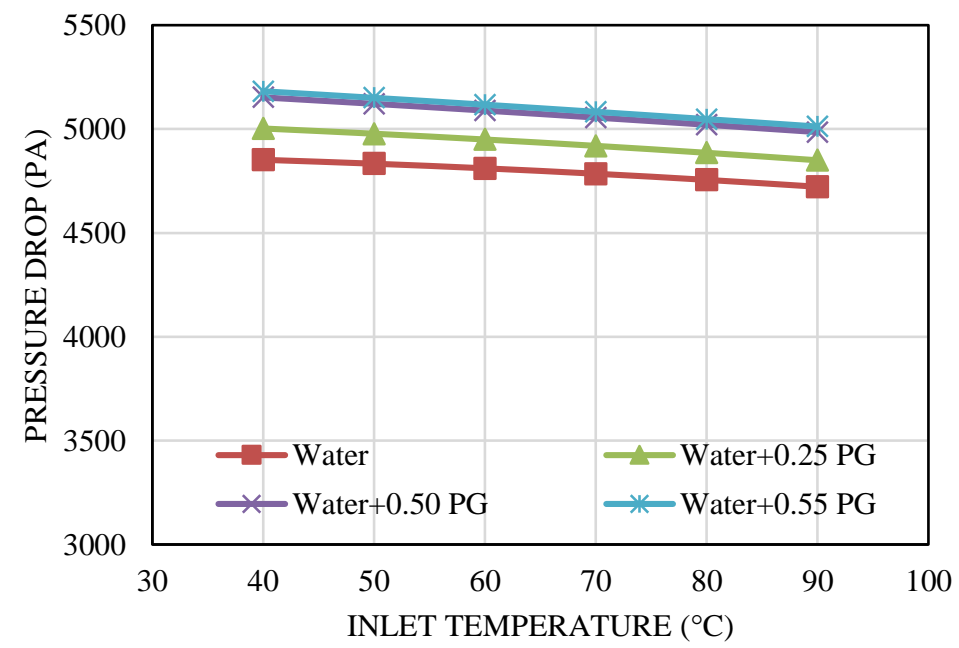

Figure 4. Variation of the pressure drop versus the variation of the working fluid inlet temperature in different volume fraction of the PG 


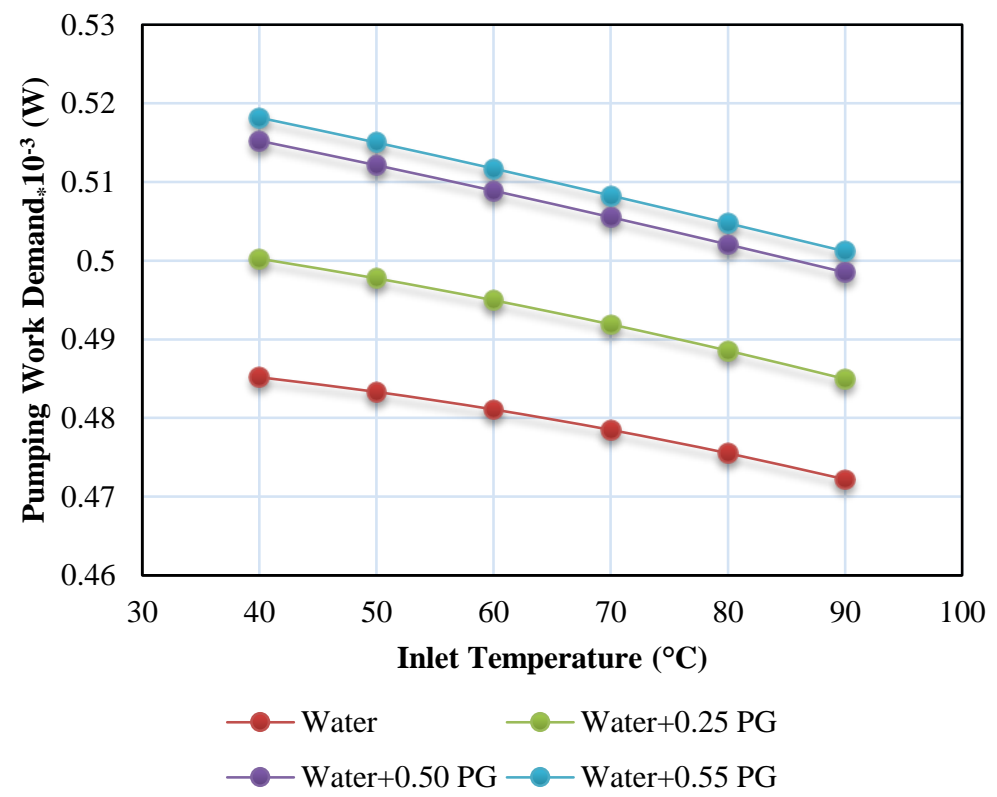

Figure 5. Variation of the pumping work demand versus the variation of the working fluid inlet temperature in different volume fraction of the PG

\section{CONCLUSIONS}

In this study, a dish concentrator with a hemispherical cavity receiver is numerically analyzed. Water/ Propylene Glycol (PG) was used as the solar heat transfer fluid. The water/PG in different volume fractions (VF) of the PG was examined consist of $0 \%, 25 \%, 50 \%$, and 55\%. The working fluid inlet temperature is investigated in ranging $0^{\circ} \mathrm{C}$ to $100^{\circ} \mathrm{C}$. The results are extracted as followings:

- The thermal efficiency and cavity heat gain decrease with increasing the working fluid inlet temperature as well as increasing the GP volume fraction in the pure water.

- The thermal efficiency of the investigated hemispherical cavity receiver has the highest amount using the pure water among the investigated solar working fluids.

- The pressure drop decreases with increasing the working fluid inlet temperature as well as decreasing the PG volume fraction. Consequently, the pure water has the lowest amount of the pressure drop among the investigated working fluids.

- The pumping work demand decreased with increasing the cavity inlet temperature as well as decreasing volume fraction of the PG in the water as the solar working fluid.

- The cavity surface temperatures are increased with increasing the working fluid inlet temperature as well as increasing the PG volume concentration in the pure water. Consequently, the application of the higher amount of PG is recommended for the Bryton cycle.

\section{APPENDIX A- THERMAL PEROPERTIS OF THE WORKING FLUIDS:}

The thermal properties of water + PG in different volume concentrations $(0 \%, 25 \%, 50 \%$, and $55 \%)$ are calculated with EES program. The thermal properties of water have been taken from Ref. [28]. Figures A1 to A4 give the specific heat capacity, the thermal conductivity, the density, and the viscosity of the examined fluids. 
Journal of Thermal Engineering, Technical Note, Vol. 5, No. 5, pp. 446-455, October, 2019

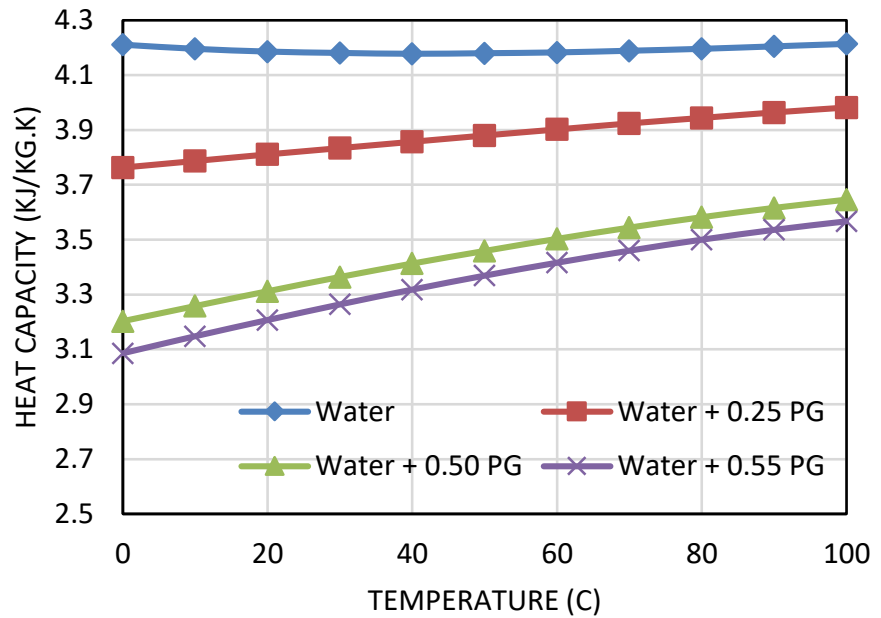

Figure A1. Heat capacity of water + PG in different volume concentrations $(0 \%, 25 \%, 50 \%$, and $55 \%)$

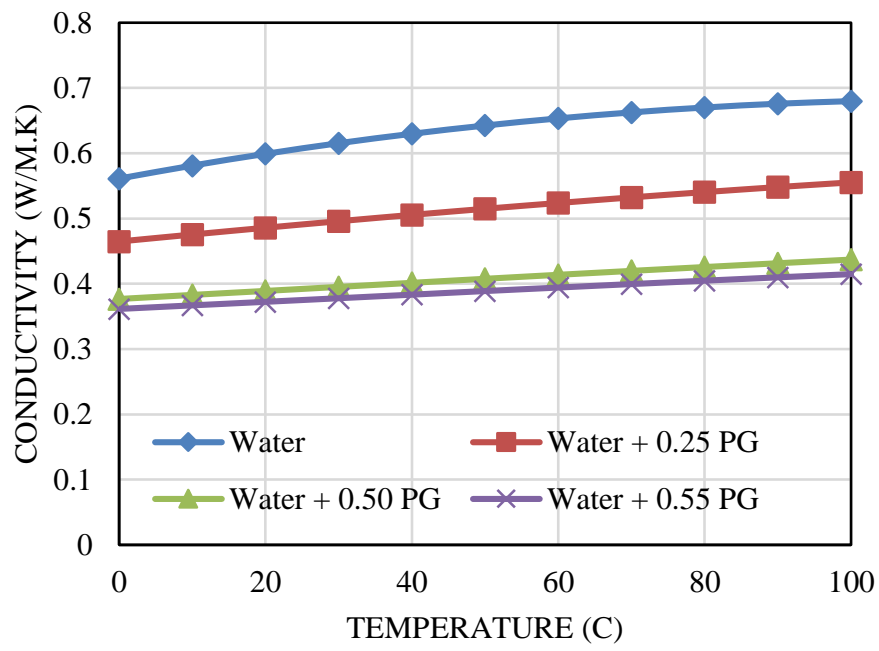

Figure A2. Thermal conductivity coefficient of water + PG in different volume concentrations $(0 \%, 25 \%, 50 \%$, and $55 \%)$

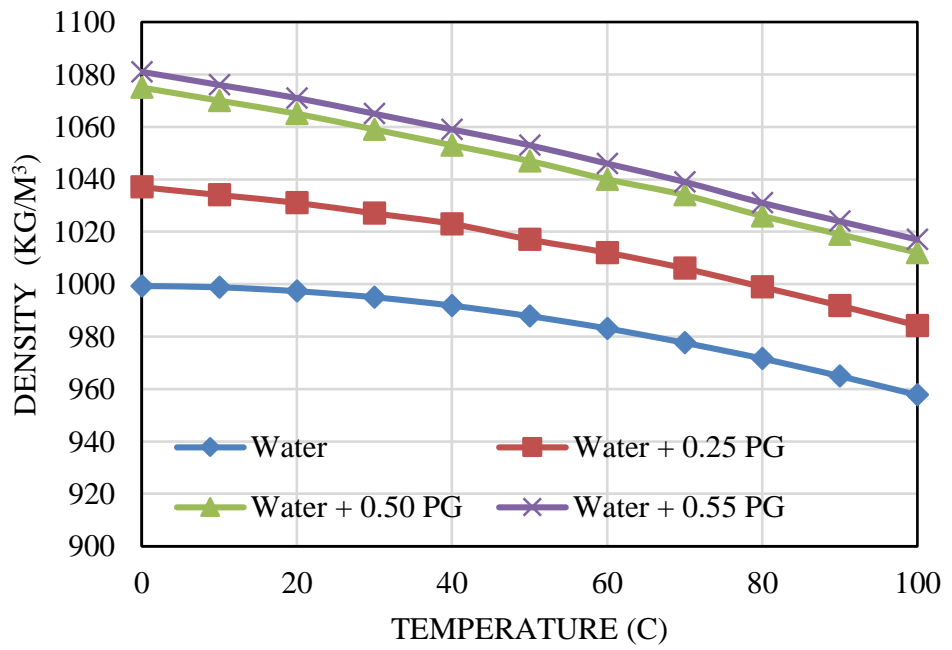

Figure A3. Density of water + PG in different volume concentrations $(0 \%, 25 \%, 50 \%$, and $55 \%)$ 


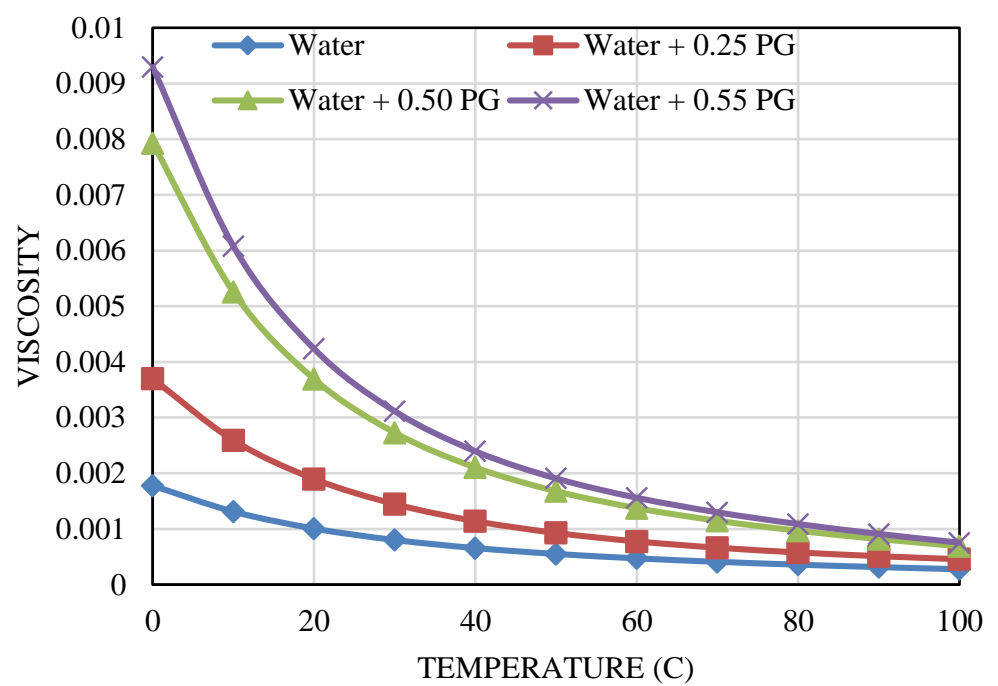

Figure A4. Viscosity of water + PG in different volume concentrations $(0 \%, 25 \%, 50 \%$, and $55 \%)$

\section{FUNDING}

Reyhaneh Loni, B. Ghobadian, and G. Najafi are grateful to the Tarbiat Modares University (http://www.modares.ac.ir) for financial supports given under IG/39705 grant for renewable Energies of Modares research group.

\section{REFERENCES}

[1] Lewis, N. S. (2007). Toward cost-effective solar energy use. science, 315(5813), 798-801.

[2] Thirugnanasambandam, M., Iniyan, S., \& Goic, R. (2010). A review of solar thermal technologies. Renewable and sustainable energy reviews, 14(1), 312-322.

[3] Loni, R. A., Asli-Ardeh, E. A., Ghobadian, B., Kasaeian, A. B., \& Gorjian, S. (2017). Thermodynamic analysis of a solar dish receiver using different nanofluids. Energy, 133, 749-760.

[4] Stefanovic, V. P., Pavlovic, S. R., Bellos, E., \& Tzivanidis, C. (2018). A detailed parametric analysis of a solar dish collector. Sustainable Energy Technologies and Assessments, 25, 99-110.

[5] Pavlovic, S., Daabo, A. M., Bellos, E., Stefanovic, V., Mahmoud, S., \& Al-Dadah, R. K. (2017). Experimental and numerical investigation on the optical and thermal performance of solar parabolic dish and corrugated spiral cavity receiver. Journal of cleaner production, 150, 75-92.

[6] Loni, R., Kasaeian, A. B., Asli-Ardeh, E. A., \& Ghobadian, B. (2016). Optimizing the efficiency of a solar receiver with tubular cylindrical cavity for a solar-powered organic Rankine cycle. Energy, 112, 1259-1272.

[8] Loni, R., Kasaeian, A., Mahian, O., Sahin, A. Z., \& Wongwises, S. (2017). Exergy analysis of a solar organic Rankine cycle with square prismatic cavity receiver. International Journal of Exergy, 22(2), 103-124.

[9] M. Günther, R. Shahbazfar, T. Fend, M. Hamdan, Solar Dish Technology.

[10] Loni, R., Asli-Ardeh, E. A., Ghobadian, B., Kasaeian, A. B., \& Gorjian, S. (2017). Numerical and experimental investigation of wind effect on a hemispherical cavity receiver. Applied Thermal Engineering, 126, 179-193.

[11] Pavlovic, S., Bellos, E., \& Loni, R. (2018). Exergetic investigation of a solar dish collector with smooth and corrugated spiral absorber operating with various nanofluids. Journal of cleaner production, 174, 1147-1160.

[12] Loni, R., Kasaeian, A. B., Mahian, O., \& Sahin, A. Z. (2016). Thermodynamic analysis of an organic rankine cycle using a tubular solar cavity receiver. Energy conversion and management, 127, 494-503.

[13] Loni, R., Kasaeian, A., Shahverdi, K., Asli-Ardeh, E. A., Ghobadian, B., \& Ahmadi, M. H. (2017). ANN model to predict the performance of parabolic dish collector with tubular cavity receiver. Mechanics \& Industry, 18(4), 408. [14] Li, H., Huang, W., Huang, F., Hu, P., \& Chen, Z. (2013). Optical analysis and optimization of parabolic dish solar concentrator with a cavity receiver. Solar energy, 92, 288-297.

[15] Jilte, R. D., Kedare, S. B., \& Nayak, J. K. (2014). Investigation on convective heat losses from solar cavities under wind conditions. Energy Procedia, 57, 437-446.

[16] Prakash, M., Kedare, S. B., \& Nayak, J. K. (2009). Investigations on heat losses from a solar cavity receiver. Solar Energy, 83(2), 157-170. 
[17] Reddy, K. S., Vikram, T. S., \& Veershetty, G. (2015). Combined heat loss analysis of solar parabolic dishmodified cavity receiver for superheated steam generation. Solar Energy, 121, 78-93.

[18] Wu, S. Y., Xiao, L., Cao, Y., \& Li, Y. R. (2010). Convection heat loss from cavity receiver in parabolic dish solar thermal power system: A review. Solar energy, 84(8), 1342-1355.

[19] Przenzak, E., Szubel, M., \& Filipowicz, M. (2016). The numerical model of the high temperature receiver for concentrated solar radiation. Energy Conversion and Management, 125, 97-106.

[20] Kaushika, N. D., \& Reddy, K. S. (2000). Performance of a low cost solar paraboloidal dish steam generating system. Energy conversion and management, 41(7), 713-726.

[21] Mao, Q., Shuai, Y., \& Yuan, Y. (2014). Study on radiation flux of the receiver with a parabolic solar concentrator system. Energy Conversion and Management, 84, 1-6.

[22] Fang, J. B., Wei, J. J., Dong, X. W., \& Wang, Y. S. (2011). Thermal performance simulation of a solar cavity receiver under windy conditions. Solar Energy, 85(1), 126-138.

[23] Reddy, K. S., \& Kumar, N. S. (2009). An improved model for natural convection heat loss from modified cavity receiver of solar dish concentrator. Solar Energy, 83(10), 1884-1892.

[24] Chang, H., Duan, C., Wen, K., Liu, Y., Xiang, C., Wan, Z., ... \& Shu, S. (2015). Modeling study on the thermal performance of a modified cavity receiver with glass window and secondary reflector. Energy Conversion and Management, 106, 1362-1369.

[25] Pavlovic, S., Bellos, E., Le Roux, W. G., Stefanovic, V., \& Tzivanidis, C. (2017). Experimental investigation and parametric analysis of a solar thermal dish collector with spiral absorber. Applied Thermal Engineering, 121, 126135.

[26] Le Roux, W. G., Bello-Ochende, T., \& Meyer, J. P. (2014). The efficiency of an open-cavity tubular solar receiver for a small-scale solar thermal Brayton cycle. Energy Conversion and Management, 84, 457-470.

[27] Schetz, J. A., \& Fuhs, A. E. (Eds.). (1999). Fundamentals of fluid mechanics. John Wiley \& Sons.

[28] C.A. Meyer, ASME steam tables: thermodynamic and transport properties of steam: comprising tables and charts for steam and water, calculated using the 1967 IFC formulation for industrial use in conformity with the 1963 international skeleton tables, as adopted by the Sixth International Conference on the Properties of Steam, American Society of Mechanical Engineers, 1983. 